\title{
Battery energy storage system (BESS) design for peak demand reduction, energy arbitrage and grid ancillary services
}

\author{
Wan Syakirah Wan Abdullah', Miszaina Osman², Mohd Zainal Abidin Ab Kadir ${ }^{3}$, Renuga Verayiah \\ ${ }^{1}$ TNB Renewables Sdn. Bhd., Level 31, PJX HM-Shah Tower, Malaysia. \\ 1,2,3,4 Institute of Power Engineering, Universiti Tenaga Nasional, Malaysia. \\ ${ }^{3}$ Advanced Lightning, Power and Energy Research Centre (ALPER), Department of Electrical and Electronic \\ Engineering, Universiti Putra Malaysia, Malaysia
}

\begin{tabular}{l} 
Article Info \\
\hline Article history: \\
Received Apr 17, 2019 \\
Revised Jul 22, 2019 \\
Accepted Aug 3, 2019 \\
\hline Keywords: \\
Battery energy storage system \\
Renewable energy \\
Bill savings \\
Virtual power plant
\end{tabular}

\begin{abstract}
Renewable Energy (RE) penetration is a new phenomenon in power systems. In the advent of high penetration of RE in the systems, several issues have to be addressed especially when it involves the stability and flexibility of the power systems. Battery Energy Storage System (BESS) has gained popularity due to its capability to store energy and to serve multiple purposes in solving various power system concerns. Additionally, several BESS can be combined to operate as Virtual Power Plant (VPP). This study will involve the design and implementation of BESS for five potential customer sites for the demonstration project and to be possibly integrated into one VPP system. The study is expected to demonstrate bill savings to the customers with BESS due to peak demand reduction and energy arbitrage savings.
\end{abstract}

This is an open access article under the CC BY-SA license.

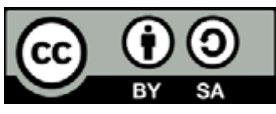

\section{Corresponding Author:}

Wan Syakirah Wan Abdullah, TNB Renewables Sdn. Bhd.

Level 31, PJX-HM Shah Tower,

No 16A, Persiaran Barat, 46050 Petaling Jaya, Selangor, Malaysia

Email: syakirahwa@tnb.com.my

\section{INTRODUCTION}

The utility world has changed drastically over the last few years. New technologies like Battery Energy Storage System (BESS) and Virtual Power Plant (VPP) have made large inroads into the utility space and no one should want to be left behind. VPP is a combination of renewable sources, Battery Energy Storage System (BESS), solar Photovoltaic (PV) and other interruptible that can supply market needs as a single power plant [1]. VPP is also a concept which includes a network of energy storages or/and distributed generation resources within an area often at the distribution side, linked together to meet utility and consumer challenges such as reduction of maximum demand, energy arbitrage, spinning reserve, frequency regulation, forecasting of sufficient supply to meet the demand, and reducing intermittency of renewable resources. With the current trend of increasing penetration of Renewable Energy (RE) such as solar energy and wind, the use of energy storage is very crucial in ensuring stability and flexibility of grid system. Penetration of RE in the power system is not a concern when the percentage is less than $10 \%$ but it will be significant once it reaches $20 \%$ from the total power generation [2-3]. To date, Malaysia has approximately $2 \%$ of RE generation sources compared to the total generation mix and targets to achieve $20 \%$ penetration by 2025 [2].

With higher penetration of RE, the system needs to be ready to solve problems related to stability and flexibility where BESS and VPP can offer such solutions. This paper presents several benefits to cater for this problem including the application of bill savings for the customers which is novel and very new 
especially in Malaysian market. Initial idea on the impact of installing BESS in terms of bill savings and serving other applications to the grid will be demonstrated together with the issues related to BESS deployment in Malaysia, which will also be highlighted.

\section{BACKGROUND}

BESS has a wide range of applications covering from generation and transmission up until behindthe-meter application. For generation side application, BESS can be used for spinning reserve, frequency regulations, black start, energy arbitrage and even as an alternative to peaking plants. For transmission and distribution sides, BESS can contribute as an asset deferral or congestion relief to the utility companies. Finally, for the behind-the-meter application, BESS can be used to fully optimise the power from solar generation either for commercial, industrial or residential customers [4-6].

There are few types of normally known battery types in the market namely Lead Acid, Sodium Sulphur, Lithium-ion and Flow Battery [3]. Each and every type have their own unique characteristics. Lead acid batteries are considered a pioneer in supplying batteries for power system. Lithium-ion is attaining popularity due to be competitiveness in pricing. Lithium-ion battery costs have declined $80 \%$ in the last five years and expected to decline 47\% Compound Annual Growth Rate (CAGR) in the next five years [6].

\section{BATTERY ENERGY STORAGE SYSTEM (BESS) APPLICATIONS}

A study conducted by the Rocky Mountain Institute summarised of up to 13 potential applications which could be offered by the BESS. The segments are illustrated in Figure 1.

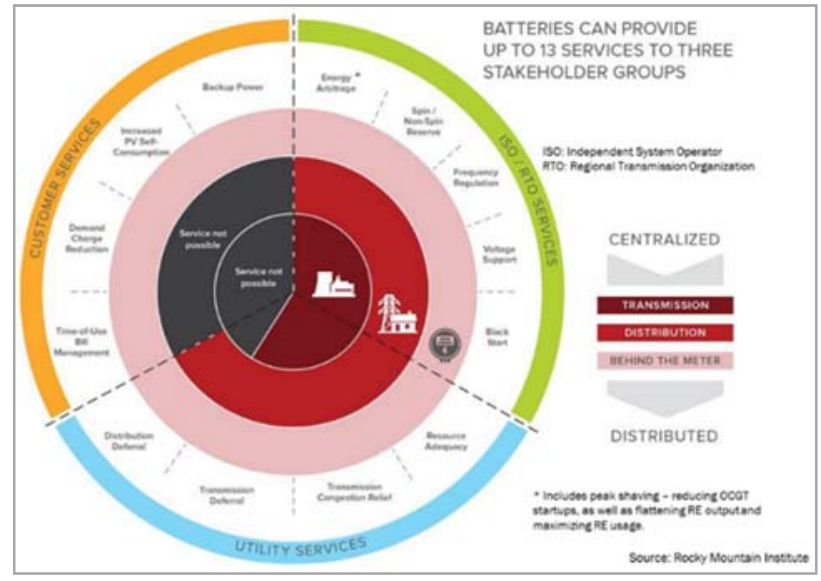

Figure 1. Various possible application of BESS [4]

\subsection{BESS for grid system operator (GSO) applications}

For grid application, BESS can be used for Spinning Reserve, Frequency Regulation, Black Start, and Energy Arbitrage and for output smoothing application for Renewable Energy [7-11]. For spinning reserve, this application can contribute savings to the total generation cost. This can be achieved by releasing spinning reserve capacity from base load generations and replacing with BESS. By maximising the base load generation that normally coming from the generations from lower tier of the merit order, savings can be achieved from lower generation cost from natural gas which is in the higher tier of the merit order[12].

For Frequency Regulation application of BESS, it can be used to maintain frequency level of the system. The advantage of BESS in terms of fast response to correct frequency of the grid system makes it a good candidate for this application [13-15]. BESS can also be an alternative for generation black start. For this application, it should be coupled with other application for the economics to work as this application has low utilisation of charging and discharging the battery. Another possible application for BESS is for Energy Arbitrage. This is possible when BESS is charged during off-peak period and discharge during peak period. This will provide savings to the total generation cost and finally passed on to the customers via lower tariff. In the case for Peninsular Malaysia this savings can be passed on to customers via the Imbalanced Cost PassThrough (ICPT) mechanism which is revised twice a year to reflect actual generation cost [16]. Another

Battery energy storage system (BESS) design for peak demand reduction ... (Wan Syakirah Wan Abdullah) 
common application of BESS is for Renewable Energy integration. Excess RE generation in the system creates natural demand for BESS as it offers stabilisation effect to the 'duck curve' effect to the system as illustrated in Figure 2.

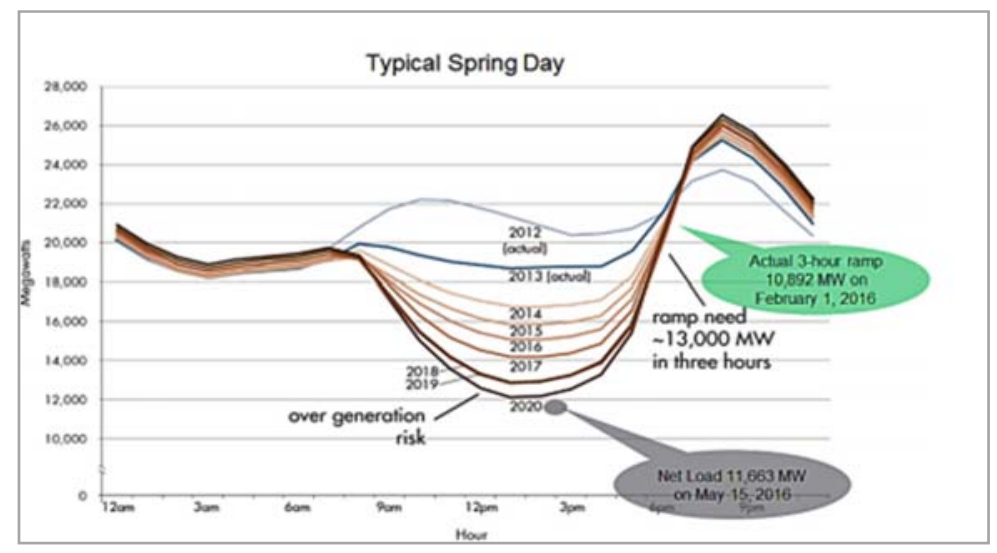

Figure 2. Various possible application of BESS [17]

\subsection{BESS for utility applications}

For this application there are few main areas of possible application of BESS namely transmission and distribution asset deferral, and congestion relief. For this possible application, with the kind of capital cost needed for BESS to replace conventional have to be at a reduced rate compared to current rate to ensure positive economics to the investment.

\subsection{BESS for customer applications}

BESS for Behind-the-meter (BTM) application, it can be considered across several services. This includes Time-of-use (ToU) bill management, to be coupled with solar rooftop and to enhance the selfconsumption capability, to be part as demand management and finally as a back-up power. At this point of time, the values have to be stacked in order to achieve positive economics to the investments. The price of BESS is estimated to fall and reach at the level where the project will be viable and offer a greater savings to the customers. Another possible viable case is when there is a bigger gap for ToU tariffs. For Malaysian customer tariff, BESS for BTM is more sensible for investments for customers with peak and off-peak tariff coupled with demand charge. With the installation of BESS, it is expected to give savings to customers' bill taking advantage of peak demand reduction and energy arbitrage effect from BESS operation. [18-21].

\section{INCENTIVE BASED REGULATIONS}

Starting from 1st January 2014, Malaysia has embarked into Incentive Based Regulations (IBR) for tariff design and management. This regulation is a structured tariff setting mechanism with fair reward to the utility for a certain quality service supplied to the customers. This regulation that has been adopted by TNB consists of three main elements, which are the Base Tariff, Imbalance Cost Pass Through (ICPT) and Performance Indicators. This tariff setting mechanism is regulated by Energy Commission (EC) of Malaysia to ensure efficient tariff is charged to the customers.

\subsection{Base tariff}

The electricity tariff review for Malaysia effective on 1st January 2014 is different from previous tariff reviews in Malaysia. The new tariff is the Base Tariff for IBR first regulatory period in Malaysia, starts from 2015 to 2017 for Regulatory Period 1 (RP1) and from 2018 to 2020 for Regulatory Period 2 (RP2). The average tariff increase for Base Tariff for Peninsular Malaysia for RP2 is increased from RP1, $39.45 \mathrm{sen} / \mathrm{kWh}$ to $38.53 \mathrm{sen} / \mathrm{kWh}$, an increase of $2.4 \%$ or $0.92 \mathrm{sen} / \mathrm{kWh}$, which mainly contributed by Single Buyer Generation cost. The increase in tariff is to cover the rising fuel cost namely piped gas, Liquid Natural Gas (LNG) and coal.

Int J Pow Elec \& Dri Syst Vol. 11, No. 1, Mar 2020 : $398-408$ 


\subsection{Imbalance cost pass through (ICPT)}

ICPT mechanism is a part of the whole IBR implementation in Malaysia. ICPT was designed to ensure that the cost related to fuel and other generation cost can be passed through to customers. ICPT rate is revised twice yearly to reflect actual generation cost to be passed through to customers in terms of rebate or surcharge in customers' monthly bill.

\subsection{Enhanced time of use tariff (EToU)}

As an extension of ToU scheme, Energy Comission (EC) launched EToU in 2016. Peak time zone under EToU is reduced to 4 hours from the existing 14 hours. Mid-Peak zone of 10 hours is introduced for Energy and Demand Charges at rates lower than the current peak rates. Off-peak zone maintained for 10 hours as shown in Figure 3. EToU is offered on an optional basis to Commercial and Industrial customers connected at Low Voltage, Medium Voltage and High Voltage. All customers who wish to enroll for ETOU scheme must enter into an agreement with TNB [22].

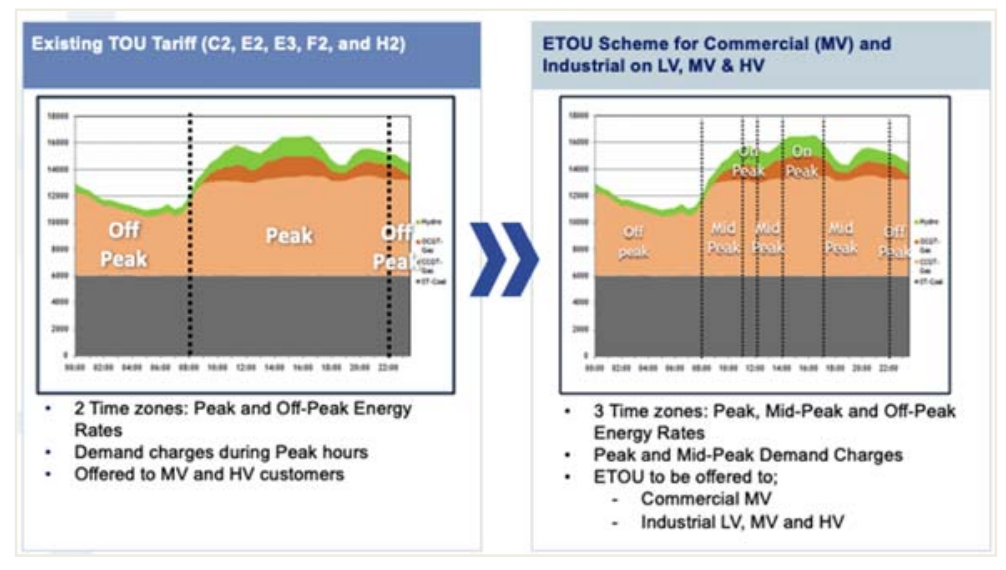

Figure 3. Enhanced time of use (EToU) Mechanism

\section{LOAD PROFILE ANALYSIS}

In this study, five customers were selected. The basis of selection is based on the tariff category. Customers under tariff category with peak demand charge and peak and off-peak tariff. These types of customers are anticipated to give benefit in terms of bill savings to the selected customers. The selected customers for the demonstration project are as follows. A research centre, a commercial customer, education campus, industrial customer and a university.

For the purpose of the study, half-hourly load profile of potential customers was extracted for a year and the peak demand and load pattern were analysed. Half-hourly load profiles were tabulated and illustrated in Figure 4, Figure 5, Figure 6, Figure 7, and Figure 8. Each and every figure for Figure 4, Figure 5, Figure 6, Figure 7, and Figure 8 is showing different profile of load data depending on the type of energy consumption of each customer type.

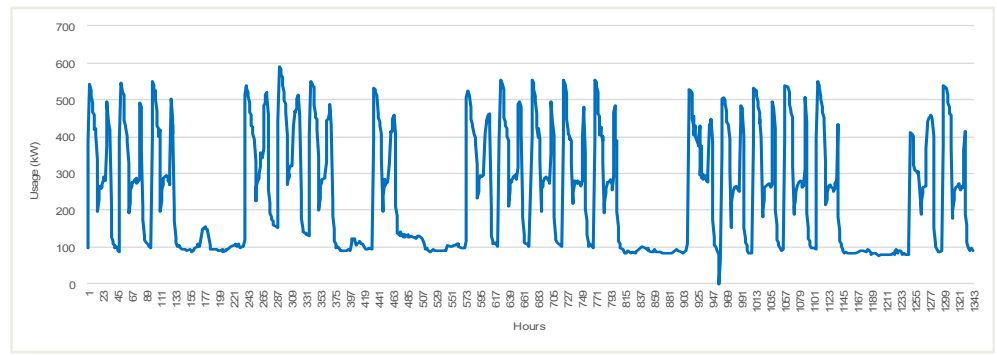

Figure 4. Typical monthly load profile for a research centre 


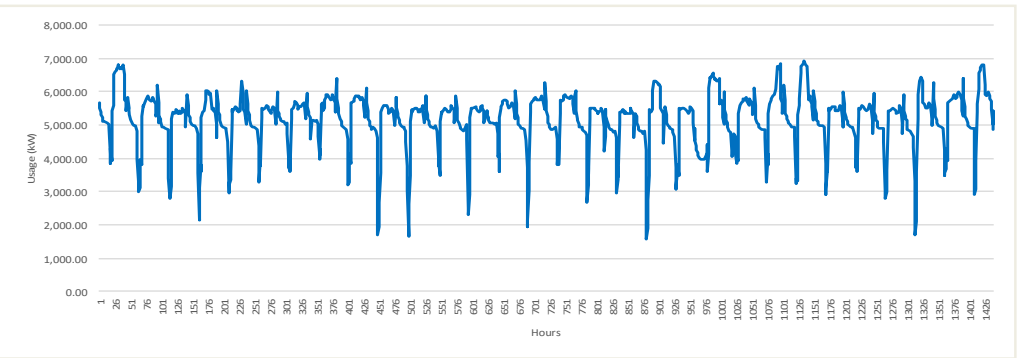

Figure 5. Typical monthly load profile for a commercial customer

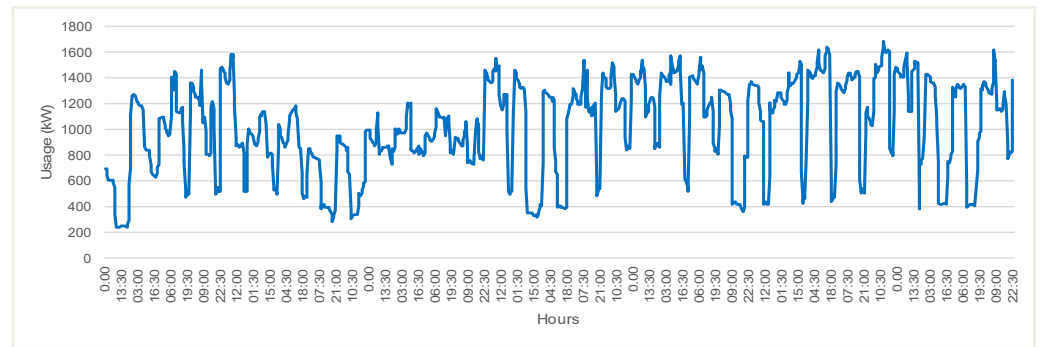

Figure 6. Typical monthly load profile for an education campus

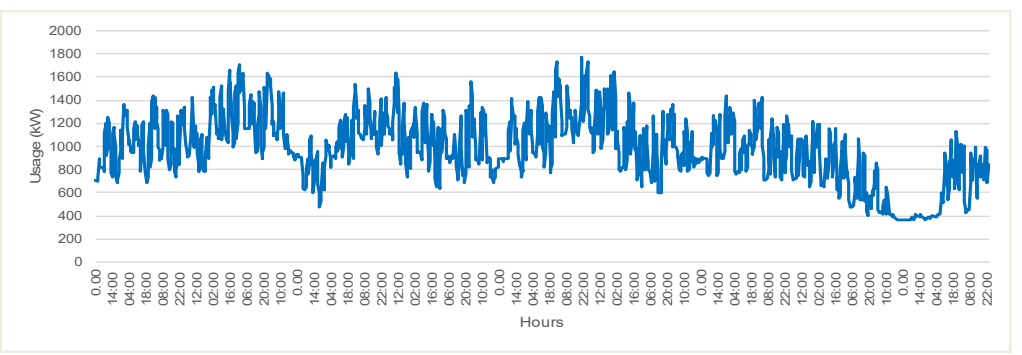

Figure 7. Typical monthly load profile for an industrial customer

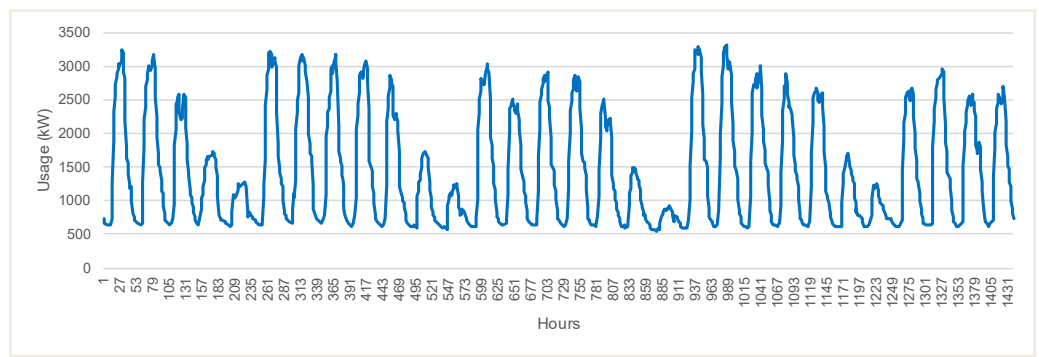

Figure 8. Typical monthly load profile for a university

\section{TECHNICAL DESIGN}

From the load profile, peak demands of each site can be determined and calculations on the targeted savings due to peak demand reductions is done using (1) and (2). Power Converter System (PCS) and BESS can be designed accordingly based on desired peak reduction.

$$
S_{P C S}=P D_{\text {hist }}(M W)-P C_{\text {target }}(M W)
$$


Where:

$$
S_{B E S S}=\sum \text { PDhist }(M W)-\text { PCtarget }(M W) \times \text { Hour }
$$

$S_{P C S} \quad$ : Desired PCS size (MW)

$S_{B E S S} \quad$ : BESS Size (MWh)

$P D_{\text {hist }} \quad$ : Peak Demand for half-hourly slot

$P C_{\text {target }}$ : Target Peak Reduction

For the capital cost of BESS, it is determined by using the following calculation [23]:

$$
C_{B E S S}=\lambda_{p w r} \times S_{p w r}+\lambda_{c a p} \times S_{c a p}
$$

Where:

$\begin{array}{ll}\lambda_{p w r} & : \text { Storage Capital Cost for Power BESS (RM/MW) } \\ S_{p w r} & : \text { Power Capacity } \\ \lambda_{c a p} & : \text { Storage Capital Cost for Energy BESS (RM/MWh) } \\ S_{c a p} & : \text { Energy Capacity }\end{array}$

Degradation and system losses have to be determined in the design process. This is to ensure that expectations of the BESS performance are considered and calculated in the design stage. The cost of degradation and losses can be computed using (3) [23].

$$
C_{\text {deg }, t}=\left(S_{\text {loss }, t}+S_{\text {charge }}+S_{\text {discharge }}\right) \times \lambda_{\text {deg }}
$$

Where:

$C_{\text {deg,t } t} \quad$ :Cost of degradation and losses

$S_{\text {loss }, t} \quad$ : Energy to cater losses

$S_{\text {charge }} \quad$ : Energy used to charge BESS during off-peak time

$S_{\text {discharge }}:$ Energy used to discharge BESS during peak time

$\lambda_{p w r} \quad$ : Cost of degradation (RM/MWh)

Studies were conducted on the load profile analysis, comparison on before and after BESS installation and VPP integration using HOMER software. Figure 9 shows a sample of design analysis in HOMER. Analysis conducted on how each site can benefit from BESS installation, either for the improvement of their electricity consumption, participation for grid ancillary service or energy trading between sites for Virtual Power Plant (VPP) mode of operation [24]. The direct benefit to the customers is the reduction of maximum demand and the energy arbitrage of Time of Use (ToU) tariff. With the possibility of solar plant connected to the customer, energy storage operator can store the energy directly from solar, as an alternative to charging the battery using off-peak tariff. For the system operating in a VPP mode, it can be used to serve the grid ancillary service such as frequency regulation.

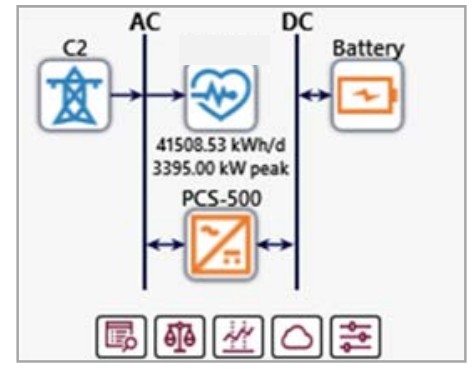

Figure 9. Sample design of BESS system in HOMER software.

For peak demand reduction, for example for a customer under $\mathrm{C} 2$ tariff, the maximum demand charge is RM 45.10 per month. Charging BESS during the low peak period and discharging during peak demand time will potentially avoid or reduce the peak demand charge. For energy arbitrage, the BESS can be charged during the peak hours and discharged during off-peak hours. The savings can be harnessed and customers will experience bill reduction. For instance, for C2 customers in Table 1, charging at off-peak hour

Battery energy storage system (BESS) design for peak demand reduction ... (Wan Syakirah Wan Abdullah) 
cost $22.40 \mathrm{sen} / \mathrm{kWh}$ and discharges at peak hour rate of $36.50 \mathrm{sen} / \mathrm{kWh}$. The difference of $14.1 \mathrm{sen} / \mathrm{kWh} \mathrm{can}$ be achieved almost immediately.

From the load profile analysis of several potential sites, it is shown that customers with peak and off-peak demand together with the maximum demand charge will enjoy most savings with BESS installation. This also results in a lower payback period to the investments.

Table 1. Tariff Rates for Malaysian Commercial Customers

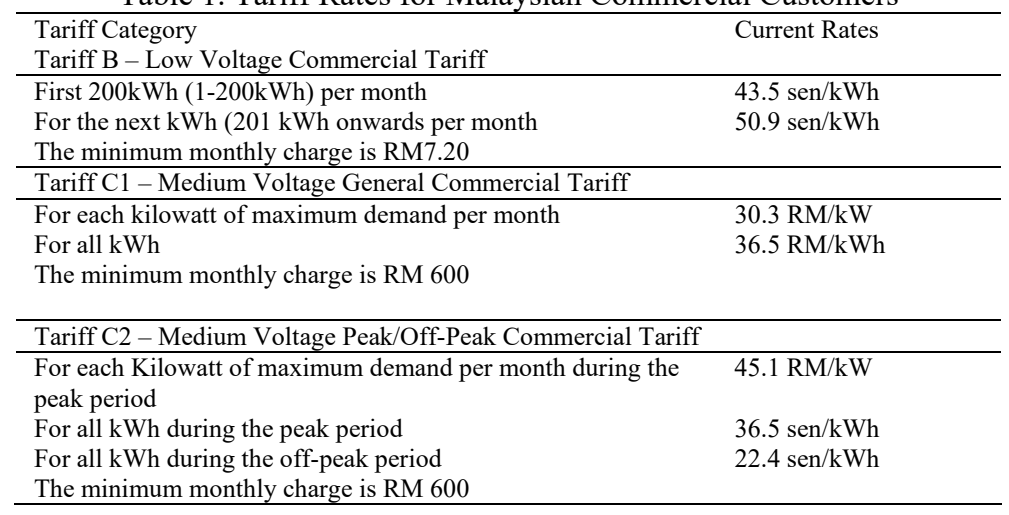

\section{BESS FOR ANCILLARY SERVICES (FREQUENCY REGULATIONS)}

For grid application, BESS can be used for Spinning Reserve, Frequency Regulation, Black Start, Energy Arbitrage and for power output smoothing application for Renewable Energy. For spinning reserve, this application can contribute savings to the total generation cost. This can be achieved by releasing spinning reserve capacity from base load generations and replacing with BESS. By maximising the base load generation that normally comes from the generations from lower tier of the merit order, savings can be achieved from lower generation cost from natural gas which is in the higher tier of the merit order.

For Frequency Regulation application of BESS, it can be used to maintain the frequency level of the system. The advantage of BESS in terms of fast respond to correct frequency of the grid system makes it a good candidate for this application. BESS can also be an alternative for generation black start. For this application, it should be coupled with other application for the economics to work as this application has low utilisation of charging and discharging the battery.

Another possible application for BESS is for Energy Arbitrage. This is possible when BESS is charged during the off-peak period and discharge during the peak period. This will provide savings to the total generation cost and finally passed on to the customers via lower tariff. In the case for Peninsular Malaysia, this savings can be passed on to customers via the Imbalanced Cost Pass-Through (ICPT) mechanism which is revised twice a year to reflect actual generation cost. Another common application of BESS is for Renewable Energy integration. This application is crucial when the penetration of RE in the power system. As Malaysia is targeting to achieve $20 \% \mathrm{RE}$ by 2025 , it is very prudent to invest in BESS for the stability of the grid system.

BESS is also possible to serve as one of the ancillary services for frequency regulation that can be offered to Grid System Operator (GSO). Malaysia Grid Code (MGC) [25] states that primary response is defined as the automatic response over the period from zero to ten seconds and must be sustained for twenty seconds. While secondary response must be available by thirty seconds from the time of frequency change to take over from the primary response and must be sustainable for at least thirty minutes [25].

Degradation and system losses have to be determined in the design stage. Losses for charging and discharging has to be considered as a round trip efficiency of the BESS.

For the deployment of the project, the integration of software and hardware of the system will take place and will take into consideration all policy, standards and licensing required by Energy Commission (EC). Finally, evaluation of the system will take into consideration the savings of electricity bill and contribution to grid frequency regulation.

\section{CHALLENGES AND ISSUES}

Among the challenges and issues of project deployment is to determine the right service for the BESS and determining the right business model for the BESS. The proposed business model is just to cater 
for peak demand reduction and energy arbitrage which can give savings to customer bill. The most economical way in designing BESS is to address few applications for instance benefit stack with grid ancillary services. With this, the benefit of the BESS installation will be more significant for instance shorter payback period or higher return on investment (ROI).

For ancillary services in Malaysia, traditionally the rate for these services is bundled under the Power Purchase Agreement (PPA) of each power generator, a new policy and guideline are needed to incentivize BESS in providing the appropriate incentive for the services to the grid. For grid application, BESS can be used for Spinning Reserve, Frequency Regulation, Black Start, Energy Arbitrage and for output smoothing application for Renewable Energy and if each of these services is remunerated accordingly, it will motivate deployment of BESS for these purposes.

For any connection to TNB system, Power System Studies (PSS) is required to determine the connection scheme, the load flow including the impact any mitigation plan for power system stability and to avoid reverse power flow to the distribution system. Based on Malaysia Distribution Code, any Distributed Generation less than $30 \mathrm{MW}$ is required to disconnect from the distribution system in the event of loss of incoming supply to avoid any unintended islanded operation.

For standard and policies, it still not established for the implementation of BESS projects. For instance, safety standards for utility-scale batteries have not been established. At the moment, it is using the safety standard for small scale batteries IEC 62133 [26]. In term of communication, installations of BESS and VPP have to comply to TNB's communication protocol and cybersecurity policies i.e: IEC 60870 addressing telecommunication issues. This is to ensure data security as all data especially the communication and control of BESS is linked to Grid System Operator (GSO) and is classified as critical and very sensitive in terms of data security. Most of data communications and control are related to charging and discharging from BESS to cater the targeted applications.

\section{RESULTS AND DISCUSSION}

The project is to demonstrate the technical and economic feasibility of BESS installation. It is also designed to demonstrate VPP to serve grid application such as frequency response. With the right optimized sizing of BESS and PCS, some customers are able to enjoy as low as 7 years of pay-back period, but some customers will have higher payback period depending on the load pattern. The payback period is potentially reduced with the anticipation of price reduction of BESS. Based on price projection by Bloomberg New Energy Finance, the price of BESS is reducing at an average rate of 5\% per year [27]. Results on benefit are tabulated in Table 2.

Table 2. Site tariff type and benefit

\begin{tabular}{|c|c|c|c|}
\hline No & Site & Tariff Type & Benefit \\
\hline \multirow[t]{3}{*}{1} & Research & Medium Voltage Peak/Off-peak & Peak demand cut \\
\hline & Centre & Commercial Tariff & Energy Arbitrage (Peak and Off-peak) \\
\hline & & C2 Tariff & Grid Frequency Regulation \\
\hline \multirow[t]{2}{*}{2} & Commercial & Medium Voltage Peak/Off-peak & Peak demand cut \\
\hline & Customer & $\begin{array}{l}\text { Commercial Tariff } \\
\text { C2 Tariff }\end{array}$ & Energy Arbitrage (Peak and Off-peak) \\
\hline \multirow[t]{2}{*}{3} & Education & Medium Voltage Peak/Off-Peak & Peak demand cut \\
\hline & Campus & $\begin{array}{l}\text { Commercial Tariff } \\
\text { C2 U Tariff }\end{array}$ & Energy Arbitrage (Peak and Off-Peak) \\
\hline \multirow[t]{2}{*}{4} & Industrial & Medium Voltage Peak/Off-peak & Peak demand cut \\
\hline & & $\begin{array}{l}\text { Commercial Tariff } \\
\text { C2 Tariff }\end{array}$ & Energy Arbitrage (Peak and Off-Peak) \\
\hline \multirow[t]{2}{*}{5} & University & Medium Voltage Peak/Off-peak & Peak demand cut \\
\hline & & $\begin{array}{l}\text { Commercial Tariff } \\
\text { C2 Tariff }\end{array}$ & Energy Arbitrage (Peak and Off-Peak) \\
\hline
\end{tabular}

Load profile after installation and the effect of peak demand reduction on the highest load month are shown in Figure 10, Figure 11, Figure 12, Figure 13, and Figure-14, where the red lines indicated that the peak has been cut by using BESS: 


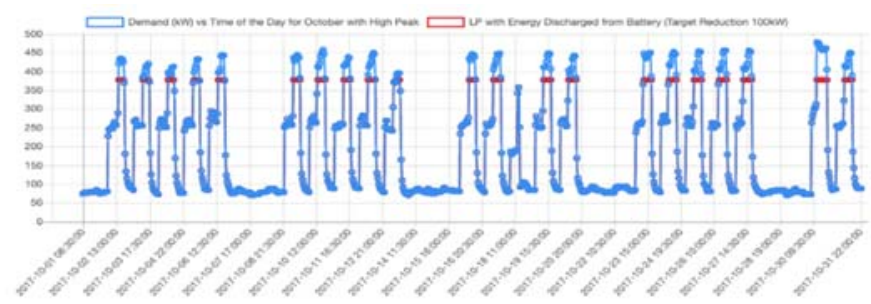

Figure 10. Typical monthly load profile for a research centre customer after BESS installation

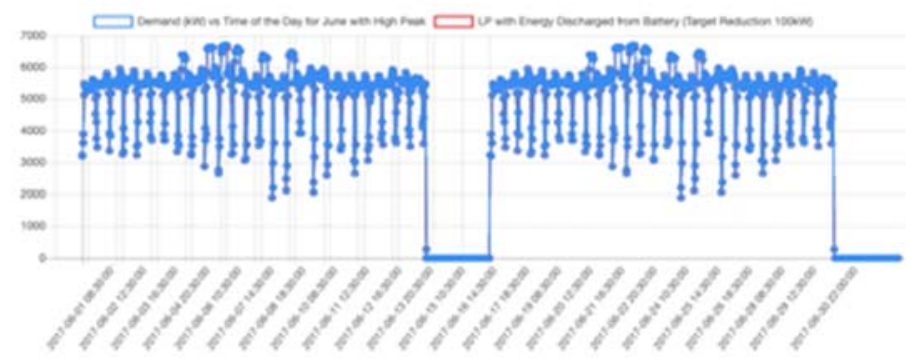

Figure 11. Typical monthly load profile for a commercial customer after BESS installation

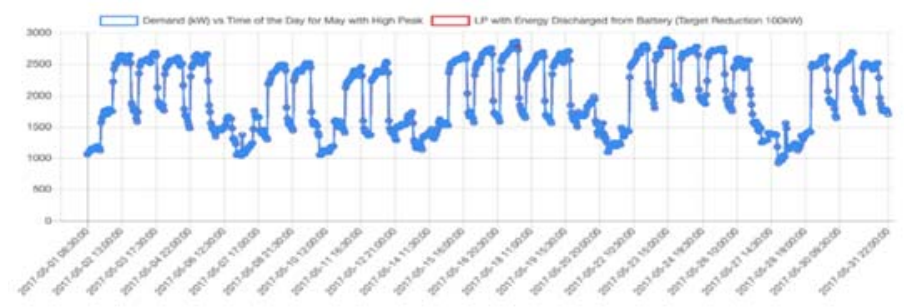

Figure 12. Typical monthly load profile for an education campus after BESS installation

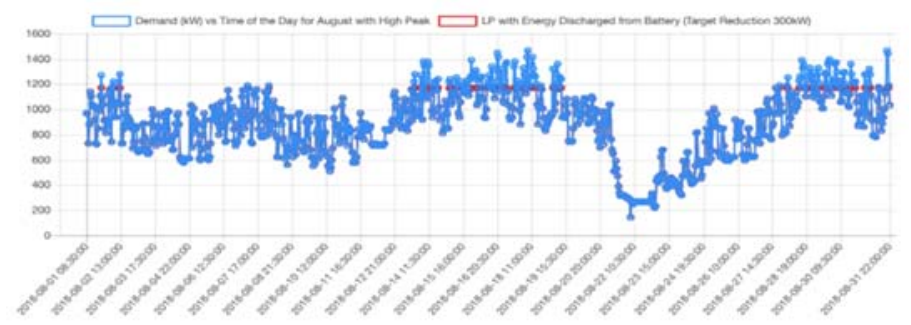

Figure 13. Typical monthly load profile for an industrial customer after BESS installation

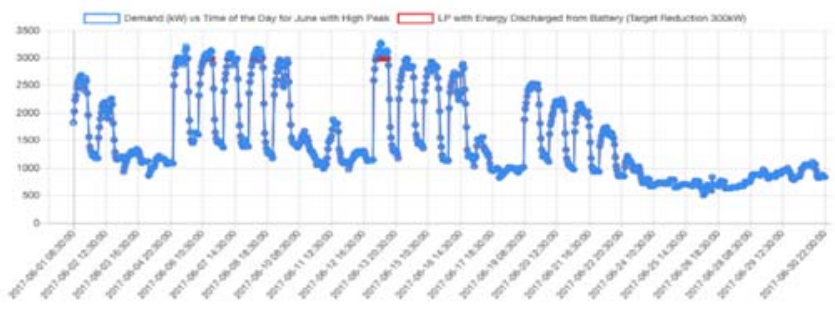

Figure 14. Typical monthly load profile for a university after BESS installation 


\section{CONCLUSION}

In conclusion, with the installation of BESS to selected customers with peak demand charge and also peak and off-peak tariff characteristics, it will benefit customers in bill savings. Additionally, the economics of BESS installation will improve with revenue stack from other ancillary services such as frequency regulations. In the country of Malaysia, such market for ancillary services is still not available because all ancillary services are embedded in the Power Purchase Agreement (PPA) rates. With this study, it has demonstrated benefits by BESS installation which is bill savings to the customers that can be the motivation for the implementation of ancillary service market remuneration.

\section{ACKNOWLEDGEMENTS}

The author would like to express her thanks to the Tenaga Nasional Berhad (TNB) via TNB Research for the research fund and data to conduct the research study and Universiti Tenaga Nasional (UNITEN), Malaysia for the financial support through UNITEN BOLD publication and internal grant fund.

\section{REFERENCES}

[1] M. J. Kasaei, M. Gandomkar, and J. Nikoukar, "Optimal management of renewable energy sources by virtual power plant," Renew. Energy, vol. 114, pp. 1180-1188, 2017.

[2] N. S. Eusoff, "Malaysia sets new goal of 20\% clean energy generation by 2025: The edge markets," pp. 1-8, 2018.

[3] M. Aneke and M. Wang, "Energy storage technologies and real life applications-A state of the art review," Appl. Energy, vol. 179, pp. 350-377, 2016

[4] G. Fitzgerald, J. Mandel, J. Morris, and H. Touati, "The economics of battery energy storage: how multi-use, customer-sted batteries deliver the most services and value to customers and the grid," Report, pp. 41, Oct 2015.

[5] M. Mcpherson and S. Tahseen, "Deploying storage assets to facilitate variable renewable energy integration: The impacts of grid fl exibility, renewable penetration, and market structure," Energy, vol. 145, pp. 856-870, 2018.

[6] B. N. E. Finance, "Battery storage : A power \& utilities perspective," 2017.

[7] B. Biegel, M. Westenholz, L. H. Hansen, J. Stoustrup, P. Andersen, and S. Harbo, "Integration of flexible consumers in the ancillary service markets," Energy, vol. 67, pp. 479-489, 2014.

[8] A. Banshwar, N. K. Sharma, Y. R. Sood, and R. Shrivastava, "An international experience of technical and economic aspects of ancillary services in deregulated power industry: Lessons for emerging BRIC electricity markets," Renew. Sustain. Energy Rev., vol. 90, pp. 774-801, Mar 2018.

[9] Y. Zhou, Z. Wei, G. Sun, K. W. Cheung, H. Zang, and S. Chen, "A robust optimization approach for integrated community energy system in energy and ancillary service markets," Energy, vol. 148, pp. 1-15, 2018.

[10] S. Nassuato et al., "Distributed Storage for the provision of ancillary services to the main grid: Project PRESTO," Energy Procedia, vol. 99, pp. 182193, Mar 2016.

[11] T. Kousksou, P. Bruel, A. Jamil, T. El Rhafiki, and Y. Zeraouli, "Energy storage: Applications and challenges," Sol. Energy Mater. Sol. Cells, vol. 120, PART A, pp. 5980, 2014.

[12] A. Castillo and D. F. Gayme, "Grid-scale energy storage applications in renewable energy integration: A survey," Energy Convers. Manag., vol. 87, pp. 885-894, 2014.

[13] A. Banshwar, N. K. Sharma, Y. R. Sood, and R. Shrivastava, "Renewable energy sources as a new participant in ancillary service markets," Energy Strateg. Rev., vol. 18, pp. 106-120, 2017.

[14] A. Majzoobi and A. Khodaei, "Application of microgrids in providing ancillary services to the utility grid," Energy, vol. 123, pp. 555-563, 2017.

[15] F. J. Heredia, M. D. Cuadrado, and C. Corchero, "On optimal participation in the electricity markets of wind power plants with battery energy storage systems," Comput. Oper. Res., vol. 96, pp. 316-329, 2018.

[16] Malaysia Energy Commission, "Electricity tariff review in peninsular Malaysia for Regulatory period 2 (RP2: 2018-2020) under incentive-based regulation (IBR) mechanism," vol. 2, pp. 42, Mar 2018.

[17] I. California, "CAISO - flexible resources fast facts," pp. 1-4, 2016.

[18] CIGRE, "The impact of battery energy storage system on distribution networks," 2018.

[19] D. Wu, M. Kintner-Meyer, T. Yang, and P. Balducci, "Economic analysis and optimal sizing for behind-the-meter battery storage," IEEE Power Energy Soc. Gen. Meet., 2016.

[20] K. Vatanparvar and R. Sharma, "Battery optimal approach to demand charge reduction in behind-the-meter energy management systems," IEEE Power Energy Soc. Gen. Meet., pp. 1-5, 2018.

[21] A. Zurfi, G. Albayati, and J. Zhang, "Economic feasibility of residential behind-the-meter battery energy storage under energy time of-use and demand charge rates," 2017 6th Int. Conf. Renew. Energy Res. Appl. ICRERA 2017, pp. 842-849, 2017.

[22] Malaysia Energy Commission, "ETOU_ST_briefing session_4nov2015_final", 2015

[23] L. Johnston, F. Díaz-González, O. Gomis-Bellmunt, C. Corchero-García, and M. Cruz-Zambrano, "Methodology for the economic optimisation of energy storage systems for frequency support in wind power plants," Appl. Energy, vol. 137, pp. 660-669, 2015.

[24] M. Zajc, M. Kolenc, P. Nem, C. Gutschi, and N. Suljanovi, "Performance evaluation of a virtual power plant communication system providing ancillary services," vol. 149, pp. 46-54, 2017.

Battery energy storage system (BESS) design for peak demand reduction ... (Wan Syakirah Wan Abdullah) 
[25] Suruhanjaya Tenaga, "Malaysia grid code," 2010.

[26] AA Portable Power Corp, "IEC62133 (2nd edition) Safety Test Standard of Li-Ion Cell and Battery," vol. 62133, pp. 1-12.

[27] New Energy Finance Bloomberg, "2018 long term energy storage outlook," 2018.

\section{BIOGRAPHIES OF AUTHORS}
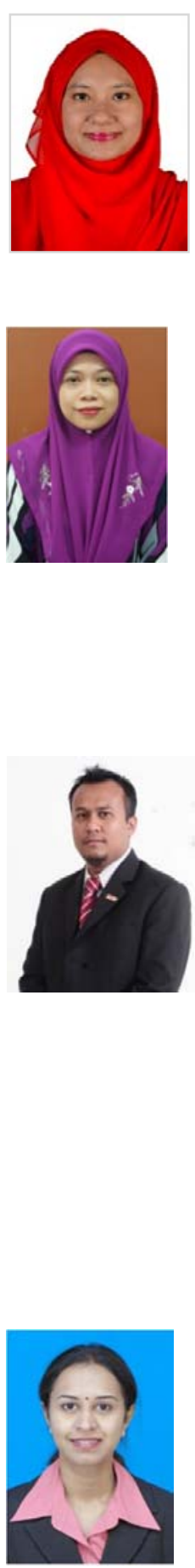

Wan Syakirah Wan Abdullah was born in Petaling Jaya, Selangor Malaysia on $6^{\text {th }}$ May 1980. She obtained her Degree in Electrical Electronics (2002) and Masters in Electrical Engineering (2012) from Universiti Tenaga Nasional Berhad, Malaysia. She is currently the Head of Business Development 2 of TNB Renewables Sdn. Bhd., a wholly owned subsidiary of Tenaga Nasional Berhad. Her experience in Power System covers generation scheduling, outage management, power system security, forecasting and Incentive Based Regulations (IBR) the tariff setting mechanism for Malaysia and recently involved in Development of Renewable Energy in Malaysia including Solar, Biomass, Biogas, Mini Hydro and Battery Energy Storage System. She is a registered Professional Engineer under Institute Engineers Malaysia (IEM) and Board of Engineers Malaysia (BEM).

Miszaina Osman received her Bachelor of Electrical Engineering Degree in 1999 and $\mathrm{PhD}$ degree in Electrical Engineering in 2004, both from the University of Southampton, United Kingdom. Miszaina is an Associate Professor under the Institute of Power Engineering, Universiti Tenaga Nasional (UNITEN). Previously, she has served as the Head of Department for Department of Electrical Power Engineering between 2009 and 2011, and also as the Deputy Dean (Academic \& Quality Assurance) and Deputy Dean (Student Affairs \& External Relations) between 2011 and 2018, in College of Engineering, UNITEN. Miszaina is a Professional Engineer (P. Eng.) and a Chartered Engineer (C.Eng.), as well as a member of Institute of Engineering and Technology UK (IET), Institute of Electrical and Electronics Engineers (IEEE) and The Institution of Engineers Malaysia (IEM). Her research interest includes power system grounding, lightning protection, and high voltage engineering. Currently, she is a member in the National Mirror Committee of IEC TC81 (Lightning Protection) and a country's representative to the IEC TC 81 Meeting, for which Malaysia is a Permanent Member. Apart from that, she is also a member in the CIGRE Working Group C4.50 on Evaluation of Transient Performance of Grounding System in Substation.

Mohd Zainal Abidin Ab Kadir received his B.Eng. degree in Electrical and Electronic Engineering from Universiti Putra Malaysia and Ph.D. degree in High Voltage Engineering from the University of Manchester, U.K, respectively. Currently, he is a Strategic Hire Professor at the Institute of Power Engineering (IPE), Universiti Tenaga Nasional (UNITEN) and a Professor at the Faculty of Engineering, Universiti Putra Malaysia. He is the Founding Director at the Centre for Electromagnetic and Lightning Protection Research (CELP), Universiti Putra Malaysia. He is also an IEEE Power \& Energy Society (PES) Distinguished Lecturer in the field of lightning and high voltage engineering. To date he has authored and co-authored over 300 journals and conference papers. He has supervised $25 \mathrm{PhD}$ and $40 \mathrm{MSc}$ students and currently $30 \mathrm{PhD}$ and 4 $\mathrm{MSc}$ are on their way. His research interests include high voltage engineering, lightning protection, electromagnetic compatibility and power system transients. Professor Zainal is a Professional Engineer (PEng), a Chartered Engineer (CEng) and Professional Technologist (PTech), as well as a Senior Member of the Institute of Electrical dan Electronics Engineers (IEEE). Currently, he is the Chairman of the National Mirror Committee of IEC TC 81 (Lightning Protection) and Local Convener of MNC-CIGRE C4 on System Technical Performance. He is also an Advisory Board Member of the National Lightning Safety Institute (NLSI) USA, Research Advisor for the African Centre for Lightning and Electromagnetic (ACLE) and Advisor to many other government agencies such as Sustainable Energy Development Authority (SEDA) and the Energy Commission of Malaysia.

Renuga Verayiah received her Bachelor of Electrical \& Electronics Engineering Degree in 2002 and Master of Electrical Engineering in 2007 from the University Tenaga Nasional, Malaysia. She obtained her PhD degree in Electrical, Electronics \& System Engineering in 2017 from Universiti Kebangsaan Malaysia, Malaysia. Renuga is currently serving as a senior lecturer at Department of Electrical \& Electronics Engineering, UNITEN and also as a Program Coordinator for Master of Electrical Engineering Program at College of Graduate Studies, UNITEN. She is a member of Institute of Engineering and Technology UK (MIET) and The Institution of Engineers Malaysia (IEM). She is also a Certified Energy Manager and a technical working committee for country's National GHG inventory and International Consultation \& Analysis (ICA) (BUR2) Malaysia. Her research interest includes power system steady state analysis, power system dynamic analysis, power system optimization and energy efficiency. 